Revista Eletrônica de Ciência Administrativa (RECADM) - ISSN 1677-7387 Faculdade Cenecista de Campo Largo - Coordenação do Curso de Administração v. 2, n. 2, nov./2003 - http://revistas.facecla.com.br/index.php/recadm/

\title{
A GESTÃO DA QUALIDADE TOTAL NA AGROPECUÁRIA: ASPECTOS INTRODUTÓRIOS
}

\author{
PROF. JOSÉ A. BONILLA(*) \\ - Faculdade de Ciências Econômicas da UFMG \\ Rua Curitiba 832 - Sala 1012 A \\ CEP 30.170-120 Belo Horizonte-MG \\ - FAX: (031) 498-3831 \\ - E-MAIL:bonilla.bhz@zaz.com.br
}

\section{RESUMO}

A Qualidade (Total) é -antes de tudo - mudança cultural. Só sobrevirão no século $\mathrm{XXI}$ as organizações que forem as melhores em seus respectivos negócios; para isto é preciso criar condições internas que assegurem sobrevivência primeiro e depois prosperidade durante o desenvolvimento daquelas.

A Qualidade Total está integrada por cinco dimensões, a saber: Qualidade Intrínseca, Custo, Atendimento, Moral e Segurança, sendo que dois conceitos básicos são: rompimento (mudança na forma de pensar, no estilo e na postura de todos os membros da organização) e satisfação total do cliente. Um terceiro conceito importante é o dos números visíveis e invisíveis.

A necessidade de implantar a Gestão da Qualidade Total em qualquer organização - incluindo os agropecuários - está justificada por uma série de motivos passados, atuais e futuros.

Desde um ponto de vista operacional, a Gestão da Qualidade possui um método básico: o PDCA, onde P ("Plan") significa planejamento; D ("Do") corresponde ao fazer, à execução das tarefas; C ("Check") envolve checagem entre a meta escolhida e o resultado obtido, e A ("Action”) implica em ação corretiva.

Figuras e tabelas ilustram o andamento do ciclo, especificamente no tocante ás metas (itens de controle), meios (fluxogramas, padrões e procedimentos operacionais), ferramentas da qualidade (representadas por uma delas: o diagrama de Ishikawa) e metodologia de análise e solução de problemas (no caso, aplicada através da análise de anomalias).

${ }^{(*)}$ Professor de Gestão da Qualidade Total. Departamento de Ciências Administrativas, Faculdade de Ciências Econômicos, Universidade Federal de Minas Gerais. Rua Curitiba 832, sala 1012A - CEP 30.170-120, Belo Horizonte - MG. 
Revista Eletrônica de Ciência Administrativa (RECADM) - ISSN 1677-7387 Faculdade Cenecista de Campo Largo - Coordenação do Curso de Administração v. 2, n. 2, nov./2003 - http://revistas.facecla.com.br/index.php/recadm/

\section{INTRODUÇÃO}

Nada é melhor para iniciar um artigo sobre Qualidade Total que o "Apelo aos Empresários Brasileiros" do Prof. Falconi, a maior autoridade nacional sobre o tema.

a) "Qualidade é uma questão de vida ou morte. Sua empresa só sobreviverá se for a melhor no seu negócio".

b) "Qualidade é mudança cultural. É preciso que as pessoas sintam a ameaça de morte da empresa, ainda que ela possa estar num horizonte de 5 a 10 anos".

c) "Qualidade é mudança cultural. É preciso tempo para conduzir mudanças (5 a 10 anos). Se você não dispuser deste tempo, não inicie esta longa caminhada".

d) "Qualidade é mudança cultural. É preciso liderança para conduzir mudança. Se você não estiver disponível, para isto, não inicie o programa".

e) “Você está pensando em Qualidade para melhorar seus resultados. Acompanhe mensalmente estes resultados através de gráficos mostrados a todos. É necessário um placar para certificar-se que você está ou não ganhando o jogo".

f) "Todos devem estar envolvidos. Todos. Para isto é necessário emoção. Reveja suas políticas de Recursos Humanos e proponha uma visão de futuro compartilhada por todos. Estamos todos no mesmo barco e temos que sobreviver.

As empresas de todo tipo, portanto as agropecuárias, estão atualmente cada vez mais ameaçadas na sua sobrevivência. Estas ameaças são, geralmente, da seguinte natureza:

a) Nosso produto perdeu atualidade pelo lançamento de um outro produto melhor e mais barato.

b) Certos países, desesperados por conseguirem divisas, baixaram o preço internacional de seus produtos fazendo uma concorrência muito forte a nossos produtos.

c) Os concorrentes já utilizam novos equipamentos que tornaram nosso processo ineficaz para o novo nível de Qualidade e Tecnologia colocado no mercado.

d) Certos países impõem exigências normativas difíceis de serem alcançadas com nosso atual processo.

e) Os concorrentes estão aplicando com sucesso a nova metodologia gerencial denominada Gestão da Qualidade Total.

Neste marco referencial, o objetivo final da implantação da Gestão da Qualidade Total numa empresa é: Criar condições internas que garantam a superação destas ameaças, assegurando a sobrevivência primeiro e a prosperidade depois, das organizações envolvidas. 
Revista Eletrônica de Ciência Administrativa (RECADM) - ISSN 1677-7387 Faculdade Cenecista de Campo Largo - Coordenação do Curso de Administração v. 2, n. 2, nov./2003 - http://revistas.facecla.com.br/index.php/recadm/

\section{CONCEITOS INTRODUTÓRIOS}

Gestão da Qualidade Total (GQT), ou seja, Total Quality Control (TQC), corresponde a um modelo gerencial aperfeiçoado no Japão, onde sobressai a figura de Ishikawa, a partir de idéias americanas, especialmente devidas a Deming e Juran, introduzidas durante a ocupação aliada naquele país depois de 1945. A sigla TQC é usada internamente no Japão, mas eles, no contato com países estrangeiros, preferem outra: CWQC (Company Wide Quality Control), ou seja, "Controle de Qualidade por toda a Empresa", para diferenciá-la de outro sistema, também chamado TQC, proposto por Feigenbaum nos E.U.A.

O TQC ou GQT está baseado em diferentes fontes, que abrangem duas linhas básicas:: uma de natureza técnica, que nasce com Taylor, se desenvolve com os métodos de controle estatístico de Shewart e se consolida com todo o conhecimento científico dos últimos 40 anos, através do trabalho dos grandes mestres: Feigenbaum, Deming e Juran, e outra, de natureza humana, apoiada nas pesquisas sobre comportamento desenvolvidas por Mc Gregor, Herzberg e Maslow e, mais recentemente, na abordagem holística representada, entre outros, por Capra e Ferguson. A montagem básica da GQT foi feita pela JUSE (Japanese Union of Scientists and Engineers).

Um aspecto fundamental da GQT é o conceito de rompimento, que implica uma mudança de forma de pensar, de estilo e de postura, envolvendo todos os integrantes da empresa, desde o mais alto até o último trabalhador. Em particular, a figura do principal da empresa assume dimensões decisivas, pois é ele, de forma intransferível, que tem em suas mãos o detonador do sucesso ou do insucesso. Com efeito, GQT é um programa do principal; portanto, ou ele rompe com o modo de pensar, sentir e agir antigo, através da assunção e comprometimento pessoal com a implantação do programa, transformando-se assim num dinâmico agente de mudanças, ou abandona a sua próprias forças, inviabilizando-o.

O conceito de Qualidade Total é amplo e dinâmico. Em princípio, ele está ligado à satisfação total do consumidor, procurada tanto de forma interna (eliminando os fatores que não agradam ao consumidor, segundo pesquisas de mercado feitas), como externas (através da antecipação das necessidades do consumidor, incorporando-se as características detectadas nos produtos e serviços). Figura 1).

Reconhece-se que a Qualidade Total está composta por cinco dimensões (Ver

a) Qualidade intrínseca do produto (ou serviço) - Em sentido amplo, refere-se especificamente às características inerentes ao produto (ou serviço) e daí o nome de intrínsecas, capazes de fornecer satisfação ao consumidor. Isto implica uma série de aspectos tais como: ausência de defeitos, adequação ao uso, características agradáveis ao consumidor, confiabilidade, previsibilidade, etc. No caso do leite, por exemplo, esta dimensão de qualidade pode ser refletida através do teor de gordura ou da densidade do produto.

b) Custo do produto ou serviço - Naturalmente que, quanto menor o preço do produto ou serviço, maior será a satisfação do consumidor. Mas isso não implica numa relação 
linear perfeita. Acontece que um elemento fundamental é o conceito de valor ${ }^{\left({ }^{*}\right.}$, ou seja, o que o consumidor estaria disposto a pagar pelo produto (ou serviço). Portanto, seu preço deverá levar em conta o valor que o produto tem para o usuário. O ideal é que o preço seja igual ou algo menor ao valor estabelecido. O custo dos insumos, tais como combustíveis, fertilizantes químicos e agrotóxicos é atualmente muito alto. É este, pois, um aspecto de vital importância na avaliação de processos que levam à melhoria da qualidade na agricultura.

Por exemplo: Se um comprador está disposto a pagar 50 centavos por um litro de leite (valor que ele the atribui) e o vendedor oferece o mesmo preço 50 centavos ou um pouco menos (45 ou 48), o negócio é interessante para ambas as partes. Já se o preço fosse 60 , talvez o comprador desista, e se fosse 40 é claro que ficaria interessado, mas não seria conveniente para o vendedor, que poderia lucrar um pouco mais.

c) Atendimento. O cliente deve receber o produto no prazo certo, no local certo e na quantidade certa. Além disso, deve ser atendido com boa vontade, cortesia e amabilidade. No caso que corresponda, deve existir uma boa organização de assistência técnica (por exemplo, no tocante a máquinas agrícolas), assim como pronta devolução de produtos defeituosos (por exemplo na agroindústria, latas de óleo de soja ou de pacotes de manteiga amassadas). No caso de produtos "in natura", principalmente os perecíveis, o prazo de entrega passa a ser um item vital.

\footnotetext{
${ }^{(*)}$ Existe toda uma técnica interessantíssima denominada "Análise de Valor", cuja aplicação na agricultura tem sido, até agora, quase nula, apesar de suas poderosas possibilidades em termos de redução de custos.
} 
Revista Eletrônica de Ciência Administrativa (RECADM) - ISSN 1677-7387 Faculdade Cenecista de Campo Largo - Coordenação do Curso de Administração v. 2, n. 2, nov./2003 - http://revistas.facecla.com.br/index.php/recadm/

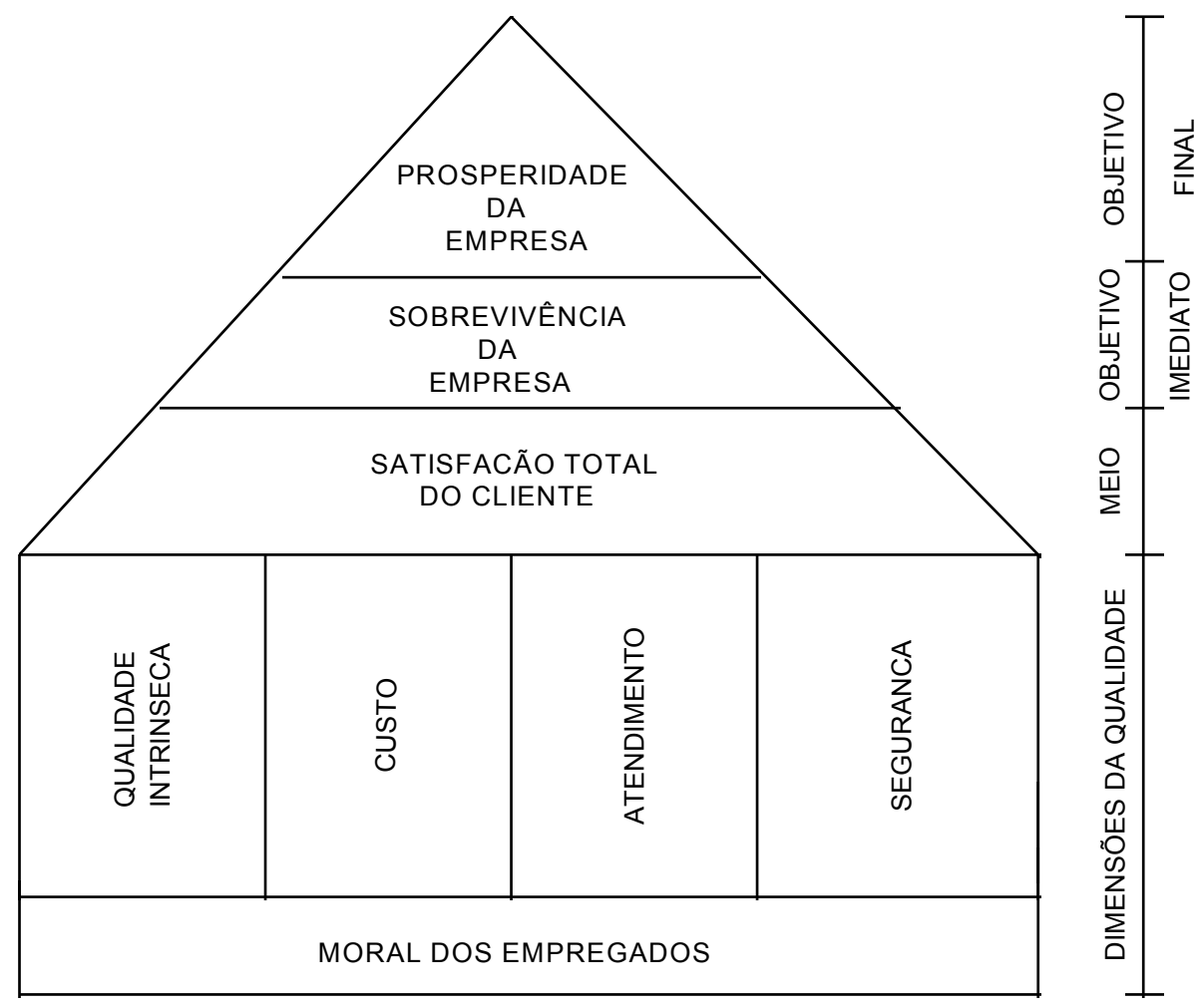

FIGURA 1 - AS CINCO DIMENSÕES DA QUALIDADE TOTAL

d) Segurança. É fundamental que o produto não ameace a saúde do consumidor, seja diretamente, através de sua ingestão, ou indiretamente, através de tratamentos feitos durante o plantio ou a criação. Na agropecuária, o nível de resíduos tóxicos contidos nos alimentos produzidos, assim como a poluição de solos e águas precisa estar necessariamente muito baixo se queremos falar de Qualidade Total.

e) Moral. Refere-se à disposição e motivação que os empregados da empresa manifestam. Para que isto aconteça, "a empresa deve se esforçar para pagar-lhe bem, respeitando-os como seres humanos e dando-lhes a oportunidade de crescer como pessoa e no trabalho, vivendo uma vida feliz" (Campos). Uma das formas de avaliar o moral é através do nível de absenteísmo.

A Qualidade Total implica explorar as profundezas, as raízes, as bases, onde a qualidade é elaborada. Muitos pensam que o grande peso da responsabilidade na obtenção da Qualidade depende - quase exclusivamente - da área de Produção. Não é verdade. A GQT refere-se à qualidade em toda a empresa. O que ocorre é que a área 
operacional é o ponto terminal visível da qualidade. Isto é um modo de dizer porque a qualidade, na realidade, é um processo circular e, portanto, sem começo nem fim. Com efeito, nela se acumulam: insumos defeituosos, mão-de-obra não treinada, projetos inadequados, imperfeitos ou incompletos, falta de comunicação com o consumidor, etc. nesse sentido, a GQT amplia o conceito clássico de controle de qualidade ("conformidade com as especificações", por exemplo: que a carcaça de boi para abate tenha um rendimento acima de $50 \%$ ), desenvolvendo uma idéia básica e fundamental: a do consumidor interno, isto é, "cada empregado é cliente do processo anterior". Desse modo, as dimensões da qualidade são revertidas também para dentro da Empresa.

Esta percepção integrada - verdadeiramente holística - leva então a uma cadeia de relações que deve ser entendida e atendida. Assim, por exemplo, a qualidade final do produto agropecuário (por exemplo leite), dependerá dos sub-processos anteriores até chegar, no caso ao empacotamento. Deste modo, o setor encarregado da alimentação dos animais tem como cliente interno o setor responsável pela ordenha e este, por sua vez, o setor encarregado do transporte de leite.

No caso do pequeno produtor, ele acaba sendo cliente interno de si mesmo, mas o conceito básico continua: na medida que os processos iniciais são melhor conduzidos, isto se reflete nos seguintes, tendo como resultado final, melhorias significativas. exemplo:

Dito de uma forma mais genérica, cuidados devem ser tomados para que, por

- O setor técnico organize o trabalho para que possa ser executado em tempo hábil pelo setor operacional (cliente interno).

- O setor de compras tem se preocupar muito com os insumos (ração, forragens, vacinas etc) para que atendam o setor de produção (cliente interno) de modo a oferecer qualidade intrínseca adequada e prazos de entrega satisfatórios, além de cuidar o aspecto vital dos custos.

- O setor de produção tem que entregar o produto agropecuário em condições e oportunidades adequadas ao setor de comercialização (cliente interno).

\section{POR QUE IMPLANTAR A QUALIDADE TOTAL?}

Há três tipos de motivos:

a) MOTIVOS PASSADOS - Eles podem se resumir em um: as empresas estão perdendo muitíssimo dinheiro já há muito tempo e perderão mais cada ano que passa, até fecharem as portas, se não mudarem sua ótica a tempo. Esta perda está representada, basicamente, pelo custo da má qualidade. Estes custos são da mais variada natureza. $\mathrm{Na}$ verdade, toda empresa deveria fazer uma auditoria para saber quanto é que ela perde por continuar seu modo rotineiro de administrar. Só para se ter uma idéia, estas perdas alcançam de 20 a $40 \%$ do faturamento, quando os custos necessários da qualidade não deveriam passar de $3 \%$ ou até, excepcionalmente, $5 \%$ daquele. Isto representa a fantástica soma de mais de 100 bilhões de dólares anuais no Brasil, se fossem acrescentadas as perdas oriundas por não produção devido a incompetência gerencial. 
b) MOTIVOS ATUAIS - A pressão social está aumentando sobre as empresas. Os sintomas são:

- lei de defesa do consumidor;

- redução das tarifas alfandegárias;

- leis de proteção ambiental;

- projetos de leis de distribuição de lucros;

- exigências de normas internacionais;

- adoção de Qualidade Total em empresas concorrentes - nacionais e internacionais - fazendo-as mais competitivas, etc.

c) MOTIVOS FUTUROS (Que em grande parte já são atuais) - Eles são também da natureza variada, tais como:

- desenvolvimento acelerado de mercados comuns, nos quais as empresas que não se adaptarem às novas modalidades de mercado não terão vez;

- aplicação acelerada da filosofia e das técnicas da Qualidade Total nas empresas concorrentes, reduzindo seus custos de forma drástica e tornando-as cada vez mais e mais competitivas;

- aumento acelerado da conscientização do ser humano, devido ao rápido desenvolvimento de seu hemisfério cerebral direito, sendo que até agora apenas usamos o esquerdo.

Outro conceito de fundamental importância é o dos números tangíveis e dos números intangíveis. Os primeiros são bem conhecidos por todo administrador e os outros são ignorados, porque fazem parte do futuro, mas eles são construídos com nossa ação presente. Um destes números intangíveis tem relação com o que acontece quando um cliente está satisfeito com o nosso produto (e nessa satisfação devem estar envolvidos todos os setores da empresa, agindo com elevados padrões de qualidade, de modo que por isso se fala em Qualidade Total). Outro número intangível está relacionado ao que acontece quando o cliente está insatisfeito com nosso produto (e esta insatisfação não pode atribuir-se, mais uma vez, a uma exclusiva incapacidade do Setor de Produção de Desenvolver um produto bom; o que está em jogo é a capacidade da Diretoria toda, para fazer da empresa um empreendimento viável). Da dinâmica desses números intangíveis dependerá não só a prosperidade de cada empresa e sim a sua própria sobrevivência.

\section{ASPECTOS OPERACIONAIS}

\subsection{Ciclo PDCA: Conceitos Básicos}

Existe um modelo gerencial básico da Qualidade Total. Ele foi conhecido inicialmente - em 1930 - como Ciclo Shewart, depois quando Deming o levou ao Japão em 1950 ficou conhecido lá como Ciclo Deming. Hoje é conhecido como o Ciclo PDCA, 
correspondentes as iniciais P de "plan" (planejar), D de "do" (fazer, executar), C de "check" (checar ou conferir), e A de "action" (ação corretiva).

O Ciclo PDCA é representado por um circulo com quatro quadrantes (Ver Figura 2).

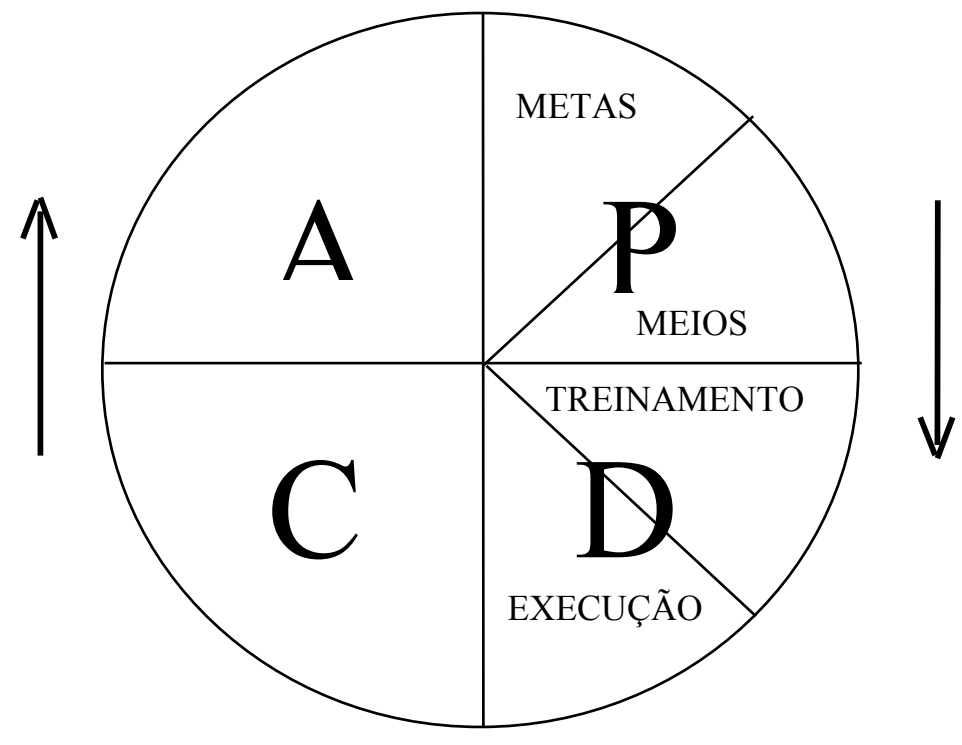

FIGURA 2 - 0 CICLO PDCA

Explicitando um pouco mais, temos:

- Planejar (P). Consiste basicamente no estabelecimento de um plano composto de metas, assim como pelos meios que permitirão atingi-las, acompanhados do respectivo cronograma.

- Executar, fazer (D). Nesta fase, o plano é executado através de tarefas específicas, devendo-se coletar dados como o propósito de posterior controle do processo. Antes da execução do plano há uma etapa fundamental: o treinamento decorrente daquelas. Obviamente ele será iniciado previamente.

A execução, o fazer, corresponde ao processo. Aqui onde as causas começam a agir sobre os efeitos. Portanto é o momento que corresponde ao monitoramento dos itens de verificação.

Conferir, checar (C). Agora o processo acabou; tem-se o produto pronto, já elaborado, manifestando-se nele uma série de efeitos. Portanto, é a oportunidade adequada para comparar as metas definidas em $\mathbf{P}$ com os resultados obtidos, medidos através da determinação da capacidade do processo. 
- Ação corretiva (A). No caso de serem comprovados desvios entre as metas estabelecidas e os resultados obtidos, a gerência deverá fazer correções tendentes a sua neutralização.

É interessante salientar que dando uma olhada rápida no Ciclo PDCA parece que corresponde a ferramentas já antigas na área gerencial. Pode até ser. Mas a análise precisa ser mais profunda e mais sutil.

Por exemplo: um trabalhador rural pode pedir ao encarregado que seja feito um ajuste num certo equipamento; um auxiliar de depósito pode pedir ao chefe que se modifique a forma de empilhar o material recebido; um empregado de escritório pode pedir que seja modificado um certo procedimento; um engenheiro agrônomo pode pedir à Diretoria que se modifiquem os critérios relativos às compras dos insumos, etc. Parece que está tudo bem. Planeja-se definindo as metas e os meios para atingi-las. Mas o drama vem depois, na segunda fase, a fase $D$ de execução, pois os responsáveis pela decisão prometem resolver o mais pronto possível, e como geralmente não comprem suas promessas, o ciclo fica quebrado.

Se realmente desejarmos trabalhar com Qualidade Total, deve-se considerar o Ciclo PDCA como o cerne do sistema, de modo que todas as ações desenvolvidas terão como orientação básica o cumprimento do ciclo. Portanto, se houve uma etapa inicial de planejamento, necessariamente haverá uma de execução e depois de controle, com ação corretiva, se for o caso. (Naturalmente que se houve algum erro no planejamento a chefia pode percebê-lo e não fornecer os meios para o andamento do Ciclo PDCA. Mas nesse caso, ela comunicará ao subordinado a natureza do impedimento para que seja feito um novo planejamento).

\subsection{O Ciclo PDCA em Operação}

Para melhor ilustração no tocante à aplicação prática do ciclo PDCA, exemplos diversificados serão apresentados logo a seguir.

\subsubsection{Planejar (P)}

a) Estabelecer as metas do processo, as quais deverão estar baseados no desempenho atual do mesmo, para o que terão que ser levantados dados sobre aquelas, definindo seu valor médio e tolerâncias. Por exemplo, Ver Tabela 1, Anexo 1.

b) Estabelecer os meios, através de definição de fluxograma do processo, assim como padrões e procedimentos operacionais, que permitam ter ao responsável pelas tarefas, todas as informações que necessita para uma correta execução das mesmas. Por exemplo, Ver Figura 3 e Tabelas 2 e 3 (Anexos 2,3 e 4). 


\subsubsection{Executar, Fazer (D)}

A partir do respectivo sistema de padrões, a tarefa é executada. Neste caso, a produção de carne, por exemplo, acontece através da alimentação, manejo, abate etc. dos animais.

Durante esta fase são monitorados os fatores (tecnicamente denominados itens de verificação) que influenciam o resultado final (rendimento em carne). Entre esses fatores podem ser considerados a composição química da ração, o conteúdo proteínico das pastagens, a disponibilidade e qualidade de água, o sombreamento etc.

Nesta fase e antes de executar as tarefas específicas, é fundamental treinar todos os funcionários, incluindo os operadores finais nos procedimentos operacionais descritos nos item 4.2.1.

\subsubsection{Conferir, Checar}

O processo "produção de carne" acabou, agora só resta comparar as metas (por exemplo: pelos menos $200 \mathrm{~kg} /$ há / ano, tecnicamente chamadas de itens de controle), com a realidade (denominada capacidade de processo). Suponhamos que o resultado obtido foi de $225 \mathrm{~kg}$ / há / ano. Como ele é compatível com a meta, tudo deverá continuar normalmente no próximo ciclo produtivo, ou se desejarmos, deverá ser colocada uma meta mais alta, por exemplo os $225 \mathrm{~kg}$ obtidos no ano anterior.

Mas se o rendimento obtido foi de, digamos, $185 \mathrm{~kg} /$ há / ano, a meta não foi atingida e isto está indicando a existência de algum problema. Basicamente, este problema pode ser de duas naturezas diferentes: na primeira, o problema acontece porque o procedimento operacional não foi corretamente cumprido; isto pode acontecer se não foi fornecido um treinamento eficiente para esta finalidade. A segunda possibilidade é que o procedimento operacional esteja errado; devemos identificar onde, como e porque isto ocorre.

$\mathrm{Na}$ realidade, na agropecuária pode ocorrer um terceiro tipo de motivo: causas incontroláveis que podem ser de natureza climática (calor ou frio excessivo, granizo, geadas, ventos fortes, inundações, seca etc.), biológica (ataque de pragas ou pestes fora de controle) ou antrópica (incêndio, devastação).

Para descobrir as causas operantes no efeito negativo, a GQT dispõe das chamadas "sete ferramentas da Qualidade". Uma delas, muito simples mas muito efetiva, é conhecida como diagrama de causa e efeito ou diagrama de Ishikawa (Ver Figura. 4, Anexo 5).

\subsubsection{Ação corretiva}

Como já foi mencionado no item 4.2.3, se o padrão não foi obedecido a ação corretiva é treinamento. Se ele foi obedecido e a meta não foi atingida, estamos com um problema. Portanto, para poder alterá-lo corretamente, precisamos identificar a causa ou 
causas fundamentais do mesmo, para o que temos que utilizar a Metodologia de Análise e Solução de Problemas (MASP) que pode ser trabalhada a três níveis: o supersimplificado (repetir a pergunta por quê, até encontrar a causa fundamental), o simplificado (análise de anomalias) ou o método completo.

Um exemplo do método simplificado (análise de anomalias) é apresentado na Tabela 4, Anexo 6).

\section{BIBLIOGRAFIA CONSULTADA}

BONILLA José A. Resposta à Crise: Qualidade Total Autêntica em Bens e Serviços. São Paulo: Makron Books. 1993, 238 p.

BONILLA José A. Qualidade Total na Agricultura: Fundamentos e Aplicações. Belo Horizonte: Secretaria de Agricultura. 1994, 344 p.

BONILLA José A. Métodos Quantitativos para Qualidade Total na Agricultura. Belo Horizonte: Secretaria de Agricultura. 1995, 249 p.

BONILLA José A. Gestão da Qualidade Total para Produtores de Café. Universidade Federal de Lavras. 1999, 183 p.

BONILLA José A. Gestão da Qualidade Total na Cadeia Produtiva do Café. Universidade Federal de Lavras. 1999 b, 423 p. 
Revista Eletrônica de Ciência Administrativa (RECADM) - ISSN 1677-7387 Faculdade Cenecista de Campo Largo - Coordenação do Curso de Administração v. 2, n. 2, nov./2003 - http://revistas.facecla.com.br/index.php/recadm/

ANEXO 1

\begin{tabular}{|c|c|c|}
\hline $\begin{array}{c}\text { DIMENSÕES } \\
\text { DA } \\
\text { QUALIDADE }\end{array}$ & ITENS DE CONTROLE & ESPECIFICAÇÕES \\
\hline & $\begin{array}{ll}- & \text { ACIDEZ } \\
- & \text { TEOR DE GORDURA } \\
- & \text { VOLUME } \\
- & \text { DENSIDADE } \\
- & \text { PROTEÍNA } \\
- & \text { pH } \\
- & \text { TEMPERATURA NA ENTREGA }\end{array}$ & $\begin{array}{l}\text { - } \leq 18^{\circ} \text { Dornic } \\
\text { - }>3 \% \\
\text { - } 1000 \pm 10 \mathrm{ml} \\
\text { - } 1030 \pm 10 \mathrm{~g} / \mathrm{l} \\
\text { - } 7,0 \pm 0 \% \\
\text { - } \leq 10^{\circ} \mathrm{C}\end{array}$ \\
\hline & - CUSTO GLOBAL POR LITRO & - $\leq 0,25 \mathrm{R} \$$ \\
\hline & $\begin{aligned}- & \text { ÍNDICE DE ATRASOS NA ENTREGA } \\
- & \text { ÍNDICE DE ENTREGA EM QUANTIDADE } \\
& \text { ERRADA } \\
\text { - } & \text { TOLERÂNCIA NO ATRASO DA ENTREGA }\end{aligned}$ & $\begin{array}{l}-\leq 1 \% \\
-\leq 1 \% \\
\text { - } \leq 30 \mathrm{~min}\end{array}$ \\
\hline & $\begin{array}{l}\text { - } \\
\text { ABSENTEÍSMO } \\
\text { - }\end{array}$ & $\begin{array}{ll}- & \leq 3 \% \\
- & \leq 1 \mathrm{Mensal}\end{array}$ \\
\hline & $\begin{array}{ll}- & \text { RESÍDUOS DE ANTIBIÓTICOS } \\
- & \text { RESÍDUOS DE BIOCIDAS } \\
- & \text { BRUCELOSE OU TUBERCULOSE }\end{array}$ & $\begin{array}{ll}- & \leq 0,01 \mathrm{ppm} \\
- & \leq 0,1 \mathrm{ppm} \\
\text { - } & \text { zero }\end{array}$ \\
\hline
\end{tabular}

TABELA 1 - ITENS DE CONTROLE RELATIVOS AO PRODUTO "LEITE TIPO C" PARA "CLIENTES CONSUMIDOR FINAL" 
Revista Eletrônica de Ciência Administrativa (RECADM) - ISSN 1677-7387

Faculdade Cenecista de Campo Largo - Coordenação do Curso de Administração v. 2, n. 2, nov./2003 - http://revistas.facecla.com.br/index.php/recadm/

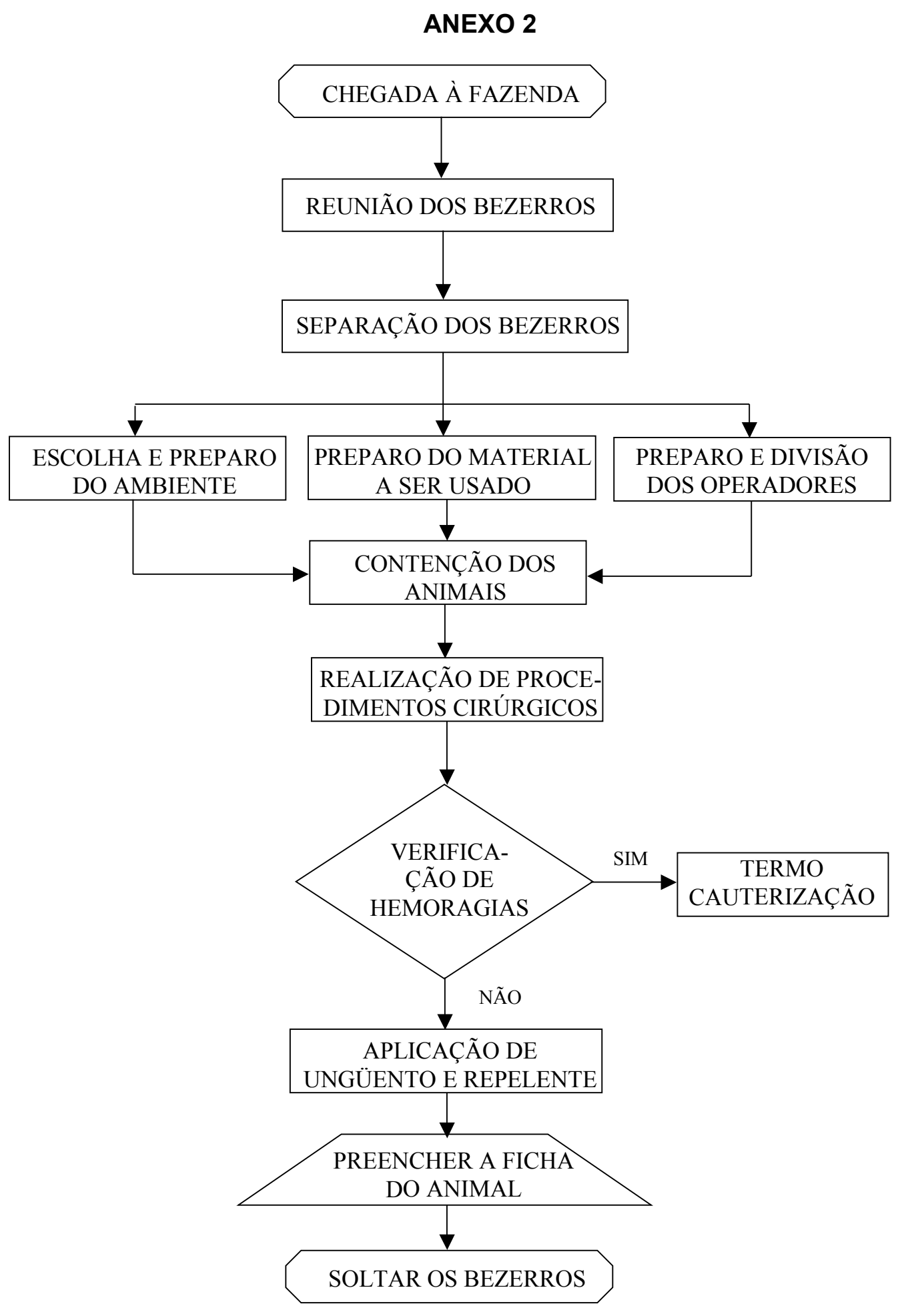

FIGURA 3. FLUXOGRAMA DE "DESCORNA DE BEZERROS” 
Revista Eletrônica de Ciência Administrativa (RECADM) - ISSN 1677-7387

Faculdade Cenecista de Campo Largo - Coordenação do Curso de Administração

v. 2, n. 2, nov./2003 - http://revistas.facecla.com.br/index.php/recadm/

\section{ANEXO 3}

\begin{tabular}{|c|c|c|c|c|c|c|c|c|c|c|}
\hline PROCESSO & \multicolumn{2}{|c|}{$\begin{array}{l}\text { ITENS DE CONTROLE } \\
\text { (PRODUTO) }\end{array}$} & \multicolumn{2}{|c|}{$\begin{array}{l}\text { ITENS DE VERIFICACION } \\
\text { (PROCESSO) }\end{array}$} & \multicolumn{4}{|c|}{ MÉTODO DE VERIFICAÇÃO DO PROCESSO } & \multicolumn{2}{|c|}{ AÇÃO CORRETIVA } \\
\hline $\begin{array}{l}\text { FLUXO- } \\
\text { GRAMA }\end{array}$ & ITEM & $\begin{array}{l}\text { ESPECI- } \\
\text { FICAÇÃO }\end{array}$ & ITEM & $\begin{array}{l}\text { VALOR DE } \\
\text { REFERENCIA }\end{array}$ & $\begin{array}{l}\text { RESPON- } \\
\text { SÁVEL }\end{array}$ & MEDIÇÕES & $\begin{array}{l}\text { INSTRUMENTO } \\
\text { MEDIDA }\end{array}$ & REGISTRO & $\begin{array}{c}\text { QUE } \\
\text { FAZER? }\end{array}$ & $\begin{array}{l}\text { QUEM } \\
\text { PROCU- } \\
\text { RAR? }\end{array}$ \\
\hline $\begin{array}{l}\text { CENTRI } \\
\text { FUGA } \\
\text { ÇÃO }\end{array}$ & -...... & -...... & $\cdots \cdots$ & ....... & ....... & $\cdots \cdots$ & $\cdots \cdots$ & ....... & -...... & $\cdots \cdots$ \\
\hline$\nabla$ & $\begin{array}{l}\text { HOMOGEINI- } \\
\text { ZAÇÃO DO TEOR } \\
\text { DE GORDURA }\end{array}$ & \multirow{2}{*}{$\begin{array}{c}35 \% \\
\pm \\
15 \% \\
\\
\text { ATÉ } 20^{\circ} \\
\text { DORNIC }\end{array}$} & \multirow{2}{*}{$\begin{array}{l}\text { DILUIÇÃO } \\
\text { OU } \\
\text { CONCEN- } \\
\text { RAÇÃO } \\
\\
\text { REDUÇÃO } \\
\text { DA ACIDEZ }\end{array}$} & $\begin{array}{c}\text { ACRESCENTAR } \\
\text { LEITE } \\
\text { DESNATADO } \\
\text { OU ELIMINAR } \\
\text { ÁGUA (ATÉ 10\% } \\
\text { DO PESO) }\end{array}$ & \multirow{2}{*}{$\begin{array}{l}\text { OPERADOR } 2 \\
\text { OPERADOR } 3\end{array}$} & $\begin{array}{l}1 \text { POR } \\
\text { HORA }\end{array}$ & BALANÇA & \multirow{3}{*}{$\begin{array}{l}\text { MAPA DE } \\
\text { VERIFI- } \\
\text { CAÇÃO }\end{array}$} & \multirow{2}{*}{$\begin{array}{c}\text { VER } \\
\text { PO-02 } \\
\\
\\
\\
\text { VER } \\
\text { PO-03 }\end{array}$} & \multirow{3}{*}{$\begin{array}{l}\text { SUPER- } \\
\text { VISOR }\end{array}$} \\
\hline $\begin{array}{l}\text { TRATA- } \\
\text { MENTO } \\
\text { DO } \\
\text { CREME } \\
\end{array}$ & ACIDEZ & & & $\begin{array}{l}\text { ACRESCENTAR } \\
\text { HIDRÓXIDO DE } \\
\text { CÁLCIO }\end{array}$ & & 1 POR & BALANÇA & & & \\
\hline$\nabla$ & SANIDADE & $\begin{array}{l}\text { BACTÉRIAS } \\
\text { COLIFORMES } \\
\text { ATÉ } 10 \text { POR MIL }\end{array}$ & $\begin{array}{l}\text { AQUECER } \\
\text { O CREME }\end{array}$ & ENTRE $75^{\circ}$ E $80^{\circ}$ & OPERADOR 4 & $\begin{array}{l}1 \text { POR } \\
\text { HORA }\end{array}$ & BALANÇA & & $\begin{array}{l}\text { VER } \\
\text { PO-04 }\end{array}$ & \\
\hline \multirow[t]{2}{*}{$\begin{array}{c}\text { ELABORA- } \\
\text { ÇÃO DA } \\
\text { MANTEIGA } \\
\end{array}$} & ........ & ........ & ........ & ........ & ........ & ........ & ........ & ........ & ........ & ........ \\
\hline & \multicolumn{2}{|c|}{$\begin{array}{l}\text { O QUE DEVE SER GARANTIDO } \\
\text { PELO PROCESSO } \\
\text { TABELA 2 - PAD }\end{array}$} & \multicolumn{2}{|c|}{$\begin{array}{l}\text { O QUE DEVE SER AJUSTADO } \\
\text { PELOS OPERADORES } \\
\text { RÃO TÉCNICO DO PROCES }\end{array}$} & \multicolumn{4}{|c|}{$\begin{array}{l}\text { O QUE DEVE SER FEITO I } \\
\text { DUÇÃO DE MANTEIGA" }\end{array}$} & \multicolumn{2}{|c|}{$\begin{array}{l}\text { O QUE DEVE SER FEITO } \\
\text { SE ALGO SAIR FORA } \\
\text { DE CONTROLE }\end{array}$} \\
\hline
\end{tabular}


Revista Eletrônica de Ciência Administrativa (RECADM) - ISSN 1677-7387 Faculdade Cenecista de Campo Largo - Coordenação do Curso de Administração v. 2, n. 2, nov./2003 - http://revistas.facecla.com.br/index.php/recadm/

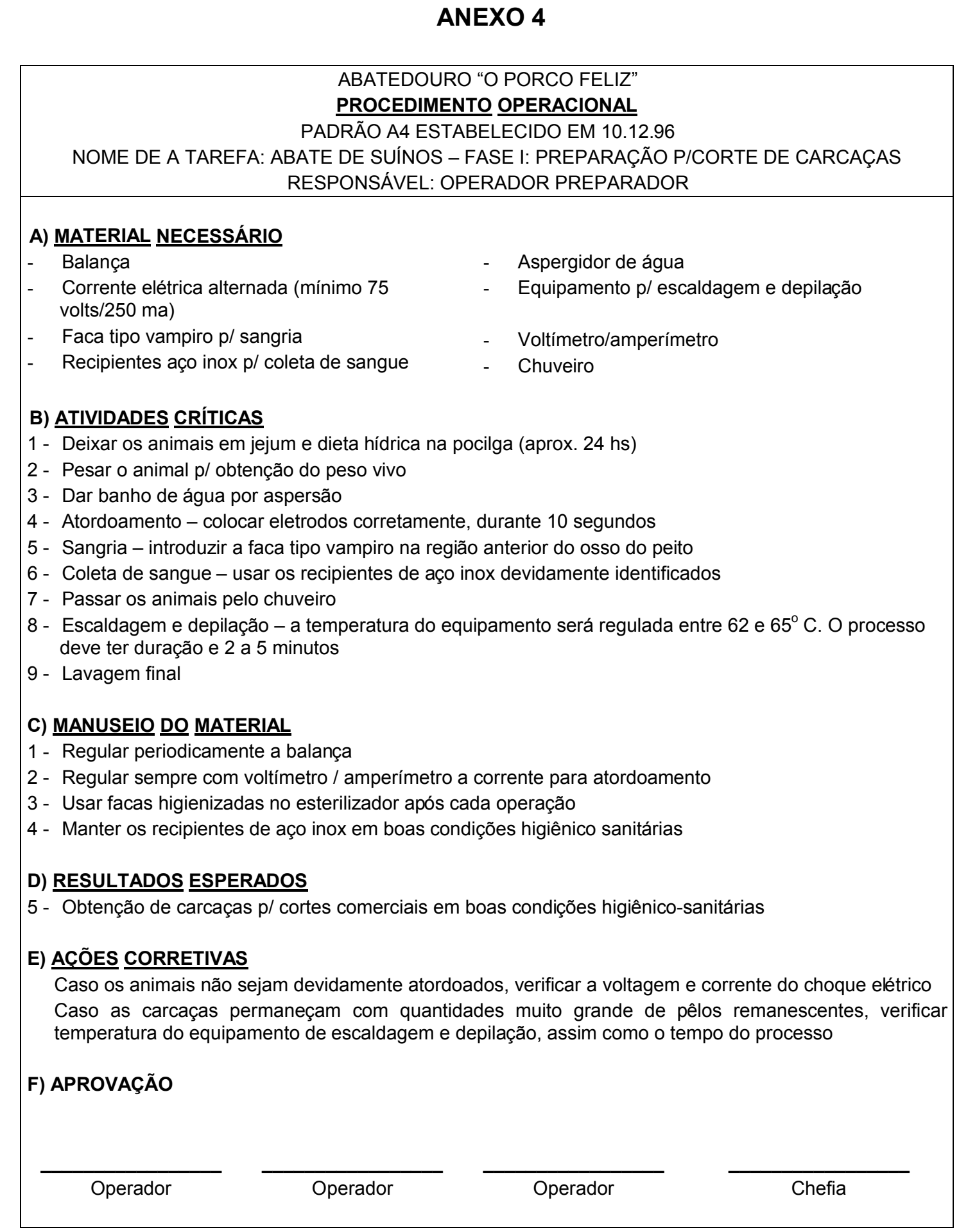


Revista Eletrônica de Ciência Administrativa (RECADM) - ISSN 1677-7387

Faculdade Cenecista de Campo Largo - Coordenação do Curso de Administração

v. 2, n. 2, nov./2003 - http://revistas.facecla.com.br/index.php/recadm/

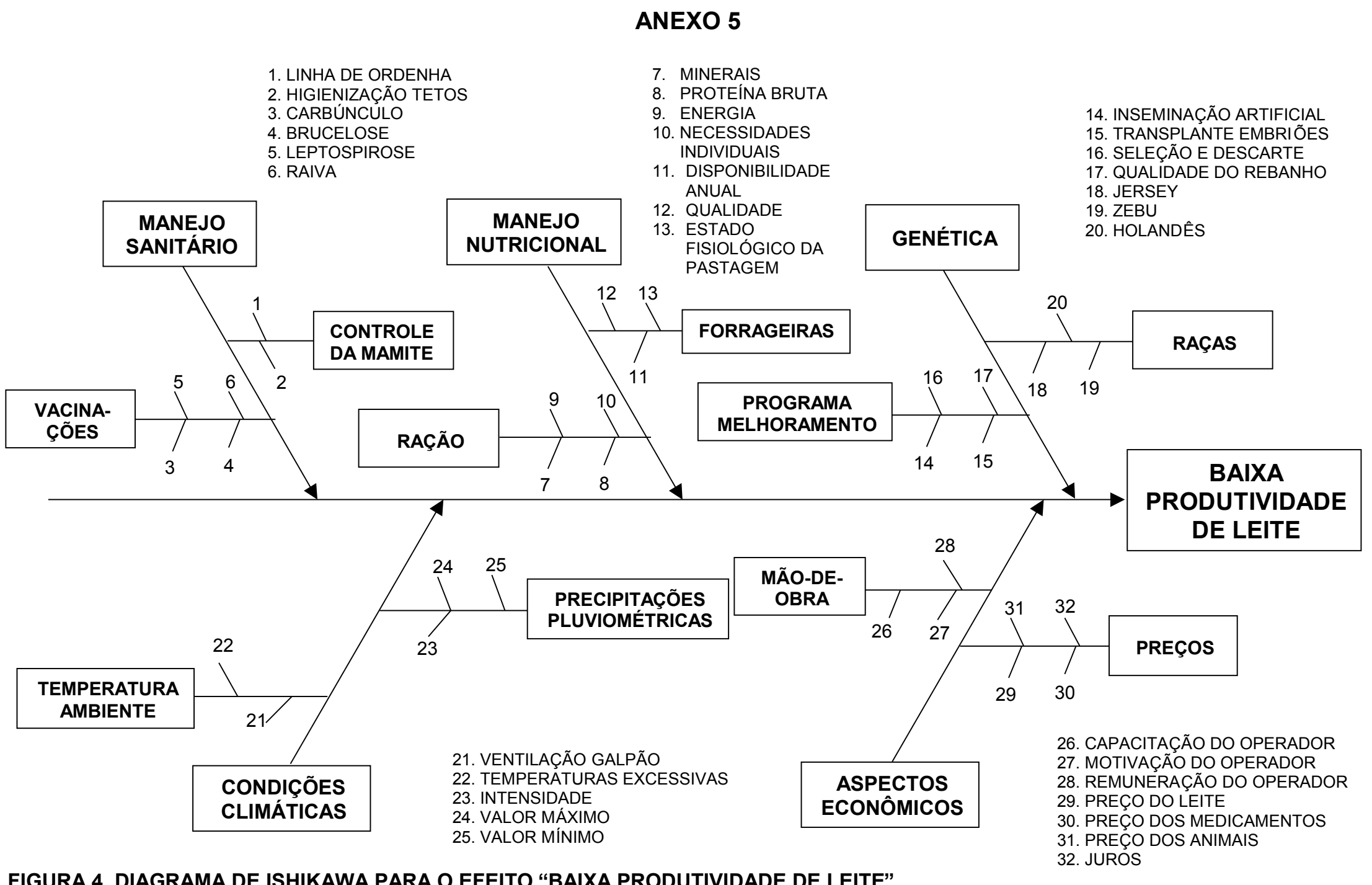


Revista Eletrônica de Ciência Administrativa (RECADM) - ISSN 1677-7387

Faculdade Cenecista de Campo Largo - Coordenação do Curso de Administração v. 2, n. 2, nov./2003 - http://revistas.facecla.com.br/index.php/recadm/

ANEXO 6

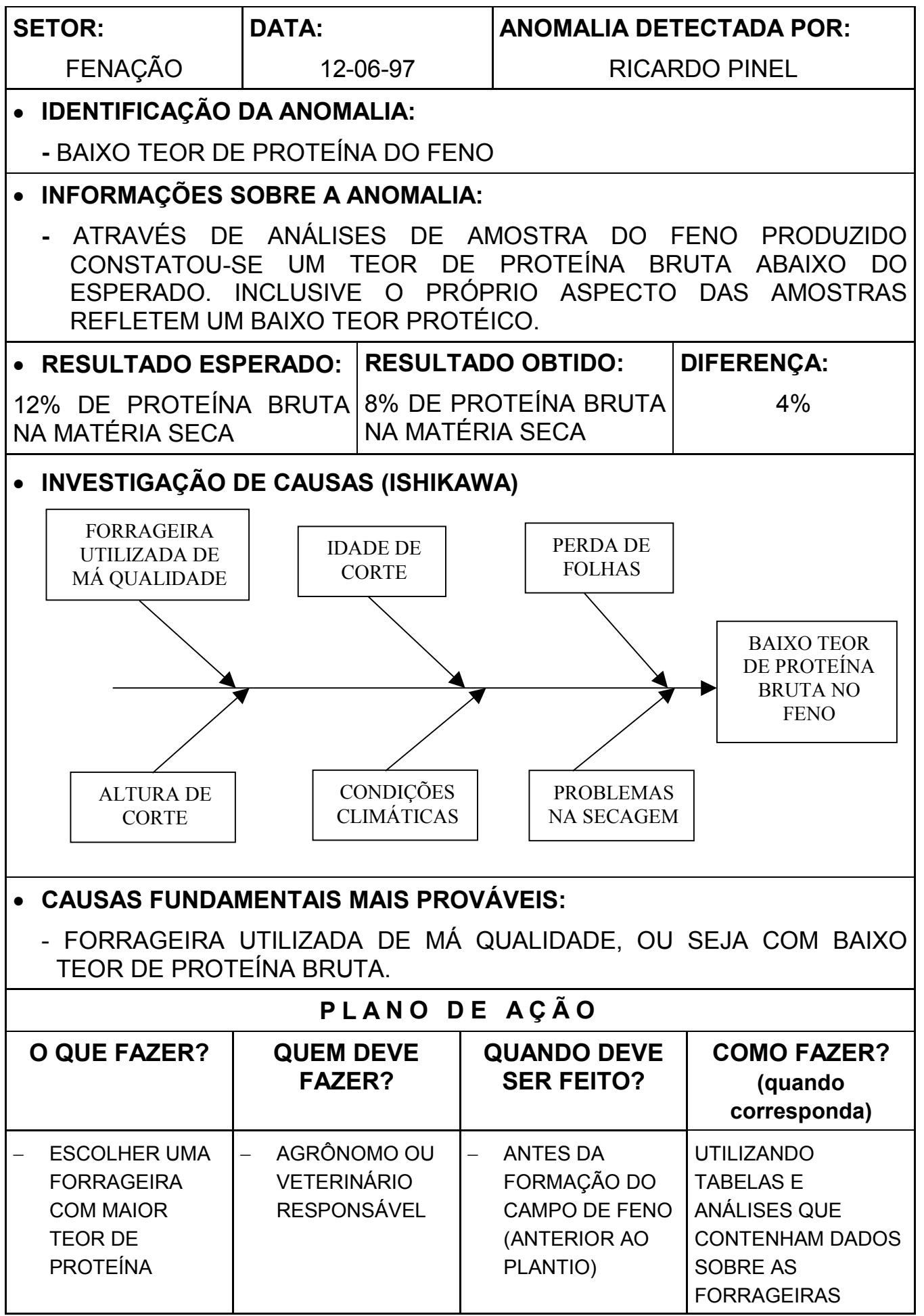

